IZA DP No. 8683

Tradable Refugee-Admission Quotas and EU Asylum Policy

Jesús Fernández-Huertas Moraga

Hillel Rapoport

November 2014

Forschungsinstitut zur Zukunft der Arbeit Institute for the Study of Labor 


\title{
Tradable Refugee-Admission Quotas and EU Asylum Policy
}

\author{
Jesús Fernández-Huertas Moraga \\ Universidad Autónoma de Madrid \\ and IZA
}

\section{Hillel Rapoport}

PSE, University Paris 1 Pantheon-Sorbonne, $M P C$, European University Institute and IZA

\section{Discussion Paper No. 8683 \\ November 2014}

\author{
IZA \\ P.O. Box 7240 \\ 53072 Bonn \\ Germany \\ Phone: +49-228-3894-0 \\ Fax: +49-228-3894-180 \\ E-mail: iza@iza.org
}

\begin{abstract}
Any opinions expressed here are those of the author(s) and not those of IZA. Research published in this series may include views on policy, but the institute itself takes no institutional policy positions. The IZA research network is committed to the IZA Guiding Principles of Research Integrity.

The Institute for the Study of Labor (IZA) in Bonn is a local and virtual international research center and a place of communication between science, politics and business. IZA is an independent nonprofit organization supported by Deutsche Post Foundation. The center is associated with the University of Bonn and offers a stimulating research environment through its international network, workshops and conferences, data service, project support, research visits and doctoral program. IZA engages in (i) original and internationally competitive research in all fields of labor economics, (ii) development of policy concepts, and (iii) dissemination of research results and concepts to the interested public.
\end{abstract}

IZA Discussion Papers often represent preliminary work and are circulated to encourage discussion. Citation of such a paper should account for its provisional character. A revised version may be available directly from the author. 
IZA Discussion Paper No. 8683

November 2014

\section{ABSTRACT}

\section{Tradable Refugee-Admission Quotas and EU Asylum Policy ${ }^{*}$}

The current EU Asylum policy is widely seen as ineffective and unfair. We propose an EUwide market for tradable quotas on both refugees and asylum-seekers coupled with a matching mechanism linking countries' and migrants' preferences. We show that the proposed system can go a long way towards addressing the shortcomings of the current system. We illustrate this claim using the recent problems regarding relocation faced by the European Relocation from Malta (EUREMA) program.

JEL Classification: F22, F5, H87, I3, K33, 019

Keywords: immigration policy, EU policy, tradable quotas, refugee resettlement, asylum seekers, international public goods

Corresponding author:

Jesús Fernández-Huertas Moraga

Departamento de Análisis Económico: Teoría Económica

e Historia Económica

Facultad de Ciencias Económicas y Empresariales

Universidad Autónoma de Madrid

Francisco Tomás y Valiente, 5

28049 Madrid

Spain

E-mail: jesus.fernandez-huertas@uam.es

\footnotetext{
* This paper was initiated at the Migration Policy Centre (European University Institute) as part of its efforts to contribute to the current debate on solidarity and asylum policy in the EU. A non-technical version of this paper appeared as RSCAS Working Paper No. 2014/101 (Rapoport and FernándezHuertas Moraga, 2014). We particularly thank Philippe De Bruycker for his careful comments and suggestions, as well as Rainer Baubock, Philippe Fargues, Bernard Hoekman, Lilian Tsourdi, Patricia Van de Peer and Alessandra Venturini. We also thank Tim Hatton, Eiko Thielemann, and participants at the CESifo Conference on International Migration, Munich, and at the Migration Policy Centre Seminar on Solidarity and Asylum Policy of the European Union at the EUI in Florence for their comments and suggestions; and Sulin Sardoschau for excellent research assistance. Jesús Fernández-Huertas Moraga received financial support from the ECO2008-04785 and ECO2012-39412 projects funded by the Spanish Ministry for Economics and Competitiveness. Hillel Rapoport acknowledges support from the Paris School of Economics "Appel à projets 2013" and from CEPREMAP.
} 


\section{Introduction}

The European Union is currently experiencing a refugee crisis: thousands of refugees are accumulating on its shores (Lampedusa, Malta, Sicily) and land borders (Greece, Bulgaria), fleeing civil war (in Libya or Syria), armed conflict or oppression. Even if these numbers are small in comparison to those of refugees hosted by States of first asylum such as Lebanon, Jordan or Turkey, this puts pressure on countries of first arrival, with thousands of persons then wandering in the EU-Schengen space and beyond. At the same time, the existing European asylum policy is overwhelmingly judged as inappropriate and is criticized not just because of its inability to address the challenges posed by the volume of refugee flows but also due to the many legal deficiencies, political inconsistencies and economic inefficiencies that characterize the current asylum system. At a legal and political level, the "Common European Asylum System" (CEAS), launched in 1999, is increasingly under fire.

For one thing, the so-called "Dublin-system" (implemented since 1997) whereby an asylum seeker is mainly under the responsibility of the country of first-entry, is more and more regarded as ill-conceived (e.g., De Bruycker et al., 2010). Under this system, an asylum seeker who entered the EU say in Greece and got arrested for illegal stay say in Belgium could be transferred back to Greece. Such a system creates disincentives for the Greek government to effectively implement the CEAS norms. Furthermore, the Dublin system prevents asylum seekers from choosing their country of asylum within the European Union, creating incentives for them to circumvent legal restrictions to mobility before their asylum claims have been examined.

A second major issue with the current system is that of "burden sharing." ${ }^{1}$ Indeed, the current system places (at least in theory) a disproportionate burden on the countries of first entry (such as Malta, Greece or Italy) that are responsible for many asylum seekers due to their geographic position. The Guidelines adopted by the European Council on 27 June 2014 underline that "the Union needs an efficient and well-managed migration, asylum and borders policy, guided by the Treaty principles of solidarity and fair sharing of responsibility, in accordance with article 80 of the Treaty on the Functioning of the European Union and its effective implementation" (guideline 5) and that "The Union's commitment to international protection requires a strong European asylum policy based on solidarity and responsibility"

\footnotetext{
${ }^{1}$ This terminology is controversial but we keep it here because of its widespread use. Some authors, and the European Council (2014), prefer to use the concept of "responsibility sharing."
} 
(guideline 7; European Council, 2014).

Under this general process, many attempts of improvements have been initiated: further harmonization of asylum law, creation of a European agency as the European Asylum Support Office (EASO), continuation of EU funding through the new Fund for Asylum, Migration and Integration, relocation of refugees across receiving countries (on the last issue, see the "Malta example" below). However, it is fair to say that progress in practice has been rather limited (see Hatton, 2011, 2012, 2013; Thielemann et al., 2010).

In this paper we propose a new perspective using market-based solutions to deal with the externality/free riding problem among EU Member States, taking advantage from the already existing institutional frameworks. We apply the idea of tradable immigration quotas proposed by Fernández-Huertas Moraga and Rapoport (2014) to the case of refugees and asylum seekers in the EU context. Indeed, providing refugee protection and asylum is a well-recognized international public good, and there is an understanding that the costs incurred should be shared more fairly, at least within the EU. Building on this idea, we explore the potential for a Tradable Refugee Quotas (TRQs) system to better coordinate national asylum policies. We supplement this system with a matching mechanism allowing for taking refugees' preferences over destinations as well as countries' preferences over refugees' types into account. This matching component, adapted from the more generic model of Fernández-Huertas Moraga and Rapoport (2014), is shown to address many of the issues that have been raised against the current EU Asylum Policy. The original paper by Fernández-Huertas Moraga and Rapoport (2014) already introduced an application to the resettlement of long-standing refugees. The present paper extends the argument and shows that the same reasoning can be applied both to refugees and asylum-seekers arriving at the EU. Refugees and asylum-seekers can be interpreted as two different "migrant types" in the original model.

The rest of the paper is organized as follows. In Section 2 we provide the empirical background for the discussion as well as evidence of "unfair" burden sharing among EU Member States. Section 3 provides the policy background in that it describes generally the evolution of the EU asylum policy over the last two decades and emphasizes the search for harmonized policies. This is followed by an outline of the existing literature on marketbased proposals in the field of refugee policy in Section 4. In Section 5 we present the model, first introducing a model of tradable refugees' quotas (TRQs) with refugees being indifferent 
among the various potential host countries and host countries being indifferent about the type of refugees they receive. We then introduce heterogeneity in refugees' preferences over their destinations and in host countries' preferences over refugees' types. Section 6 serves as an illustration for possible implementation building on the well-documented example of Malta and concludes the paper.

\section{The Numbers}

The EU receives around 300,000 asylum claims per year, about one third of the total registered in the world (see Figure 1). More than three quarters (79\%) of the stock of asylum seekers in the EU in 2012 accumulated in only six destinations countries: Germany, France, Greece, Austria, UK and Sweden. A similar picture emerges from the 2012 numbers on refugees in Europe (see Figure 2). ${ }^{2} 87 \%$ of the 1.3 Million refugees in the EU are hosted by Germany, France, UK, Sweden, Italy and Austria and $44 \%$ of them reside only in Germany.

Figure 1:

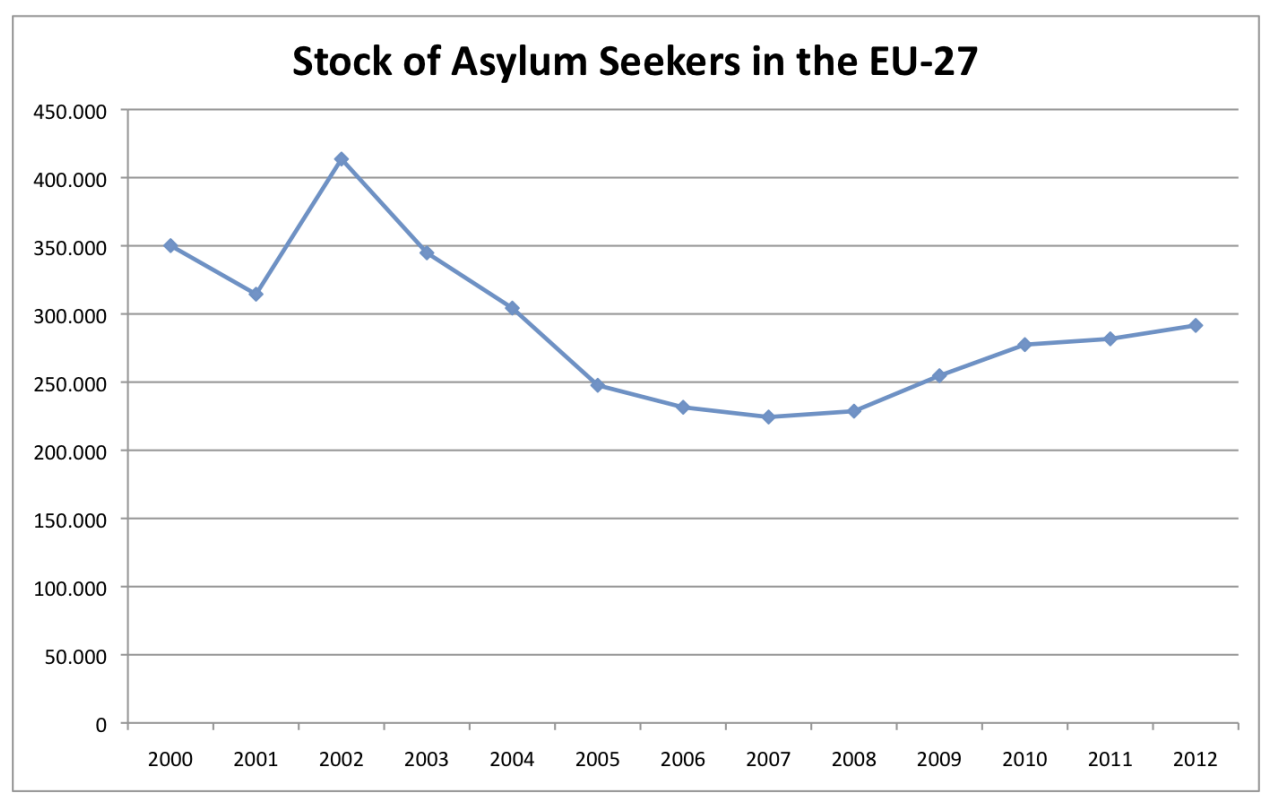

Source: own calculations on end-of-year pending applications from UNHCR (2013)

\footnotetext{
${ }^{2}$ Refugees are either people who came to Europe as asylum seekers and were granted asylum, or people who were in refugee camps outside of the EU, granted refugee status by the UNHCR and successfully applied for resettlement in one of the EU countries.
} 
Figure 2:

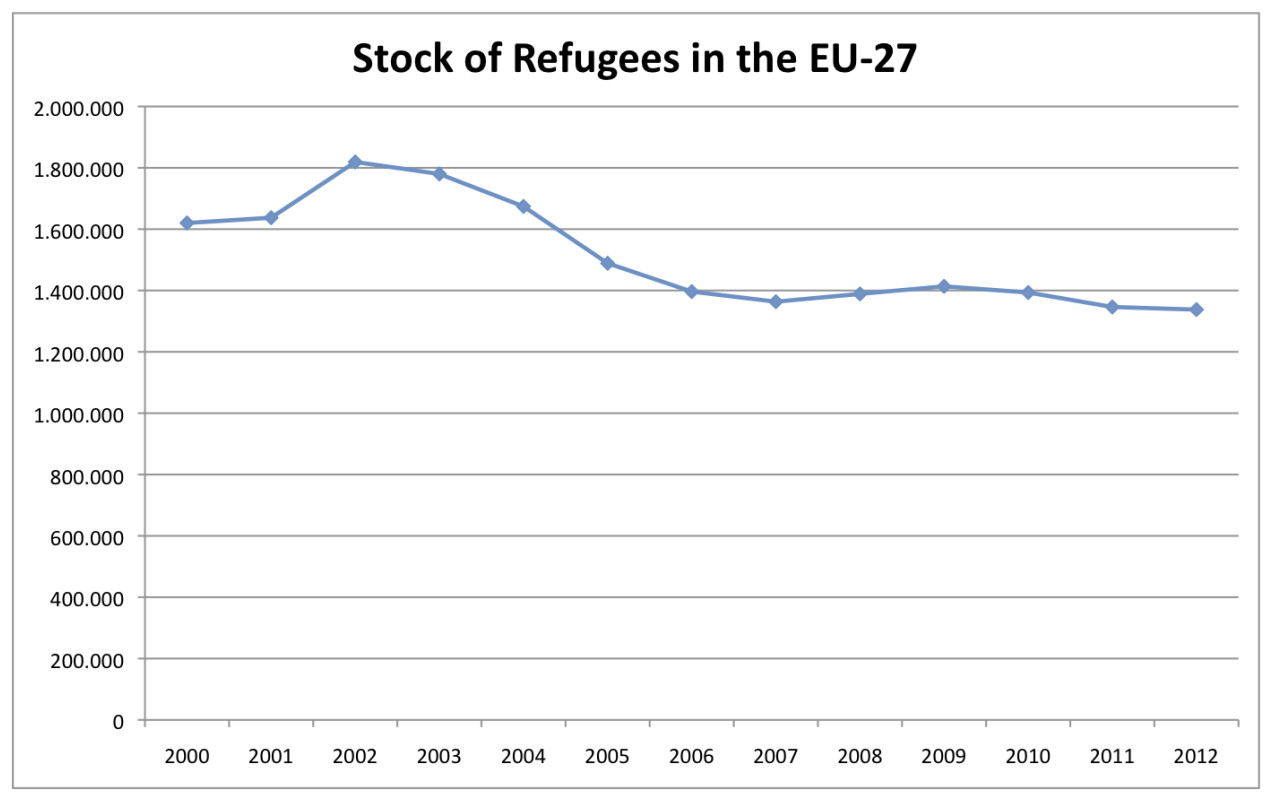

Source: own calculations from UNHCR (2013)

The allocation of immigrants within the European Union still seems to present itself as a black box. The lack of information on the mobility of non-EU nationals within the European Union has made it difficult to trace back the mechanisms under which refugees and asylum seekers locate themselves. For example, in a recent report, the European Migration Network documents recent trends of intra-EU Mobility of third-country nationals (European Migration Network, 2013). However, those estimates are not able to capture non-EU citizens that are in a state of transition regarding their legal status. Often, those immigrants vanish from the official figures. This holds especially for rejected asylum seekers willing to avoid removal. For example, only about one fourth of the 22.5 thousand asylum application decisions in Italy in 2012 were positive (UNHCR, 2013), the rest being rejected.

Indeed, the accumulation of immigrants in certain locations is disproportional to the capacities of the host countries. In their Statistical Yearbook, the UNCHR ranks host countries regarding certain indicators: the refugee to GDP ratio, refugee per 1000 inhabitants or per 1000 square kilometers. Even among the big six host EU Member States there are tremendous differences regarding their financial, demographic and geographic capacities. Whereas Germany's refugees to GDP (PPP) per capita ratio amounts to $\$ 15.31$, comparable countries such as France have a ratio of only $\$ 6$, or even as low as $\$ 0.57$ in the case of 
Belgium (UNCHR, 2013). Compared to their geographic and population size Germany, Sweden and Switzerland host a relatively large number of refugees. These numbers reveal that the allocation of refugees does not reflect the "fair burden sharing" concept put forward by the European Union, as we show in more detail in Section 3.2.

\section{EU Asylum Policy}

The Dublin Convention of 1990 established the principle of asylum in the country of first entry as a cornerstone of the European Asylum Policy. Since then, the "Dublin System" has been under attack. Its initial aim was to "clearly allocate responsibility for the examination of asylum application." However, the past two decades have shown that the resulting regulation i) was unable to cope with the striking inequality of refugee treatment across the EU, ii) did not improve the integration prospects of asylum seekers, and iii) failed to implement safeguards to protect them. In addition, the Dublin System inherently counteracts the "fair sharing perspective" and operates in a highly ineffective and costly manner (De Bruycker et al., 2010). In this section we briefly review the evolution of the EU Asylum Policy of the last two decades or so, which can be characterized by a quest for elusive harmonization and no real interest for fair burden sharing procedures.

\subsection{Harmonization}

In recognition of the shortcomings of the Dublin system and in an attempt to harmonize EU policies, many reforms have been initiated in particular since 1999. Two generations of directives have been adopted in order to harmonize the European Asylum Policy. The Asylum Procedures Directive sets out rules on the whole process of claiming asylum, including on: how to apply, how the application will be examined, what kind of assistance can be provided to asylum seekers, how to appeal and whether the appeal will allow the person to stay on the territory or how to deal with repeated applications (De Bruycker et al., 2010). These instruments try to ensure a coherent procedural system within the EU. The Reception Conditions Directive attempts to deal with the divergence in the practice of treating

asylum seekers. It ensures that applicants have access to housing, food, employment, as well as medical and psychological care. The Qualification Directive specifies the grounds for granting international protection. 
De Bruycker et al. (2010) explain how difficult it becomes to monitor the implementation of these directives by individual countries. Existing assessments are problematic due to lack of data but they tend to point out at Member States circumventing the spirit of the directives by taking advantage from its vagueness in crucial points. For example, regarding the Asylum Procedures Directive, De Bruycker et al. (2010) note "as regards survivors of torture, the Directives silence on the special needs of this category of applicants in combination with provision allowing Member States to treat cases as manifestly unfounded and omit a personal interview, have the potential to produce errors upon the asylum decision making."

Additionally, some of the shortcomings of the Dublin System have been revised not only to take into account the interests of asylum seekers but also to better address situations of particular pressure of Member States' reception capacities and asylum systems. The Temporary Protection Directive was introduced in 2001 with the ambition to create a common EU basis to manage in case of a large influx of displaced persons fleeing their country of origin. However, this directive has never been implemented (in contrast to the similar-in-spirit Temporary Protected Status in the United States, which has been invoked, for example, to prevent deportation of undocumented immigrants following the earthquakes in El Salvador in 2001 or Haiti in 2010).

Finally, the European Union has set up systems to promote informational exchange across Member States. The Eurodac regulation registers the fingerprints of all asylum seekers to prevent multiple claims. The Visa Information System facilitating information exchange across Member States and tracing back visa applications can also be used for the purpose of the asylum policy.

\subsection{Burden Sharing}

In addition to attempts to harmonize EU refugee policies, there is also an increasing demand for fair "burden sharing." The EU has taken some initiatives to address this issue since the early 2000s. In December 2011 the European Commission issued a communication "on enhanced intra-EU solidarity in the field of asylum" (European Commission, 2011) that has been followed by conclusions on a "Common framework for genuine and practical solidarity towards Member States facing particular pressures on their asylum systems" adopted by the Justice and Home Affairs Council in March 2012 (Council of Ministers of the European Union, 2012). The European Refugee Fund covered the financial component of the distri- 
bution problem. Created in 2000, the fund hoped to increase the financial solidarity among member countries with an annual budget of 105 Million Euros for 2008-2013. Recently, the European Refugee Fund has been reorganized for the years 2014 to 2020 and is now replaced by the Asylum, Migration and Integration Fund and the Internal Security Funds whose annual budget amounts to approximately 10.9 million Euros.

In December 2013 the European Council emphasized the importance of the EU Resettlement Program, following an initiative of the EU Parliament in 2012. This initiative was created to encourage resettlement of refugees by EU Member States. Despite its declared importance, the EU has failed to implement the program on a large scale. For example, up until December 2013, only 0.54\% of all Syrian refugees benefited from the initiative (Balleix, 2014). Nevertheless, in 2012 about 4,500 refugees were able to benefit from the Resettlement Program (see Table 1), which meant just above $5 \%$ of the total number of refugees resettled in the world and $9 \%$ of the number of asylum applicants that were granted refugee status in the EU that year. ${ }^{3}$

\section{Table 1:}

\begin{tabular}{|l|c|c|}
\hline \multicolumn{3}{|c|}{ EU Member States resettlement quota 2012 and 2013} \\
\hline Member State (pro year) & 2012 total quota & 2013 total quota \\
\hline Belgium & - & 100 \\
\hline Czech Republic & 40 & 40 (tbc) \\
\hline Denmark (multi-year programme 2012-2013) & 500 & 500 \\
\hline Finland & 750 & 750 \\
\hline France & 100 & 100 \\
\hline Germany & 300 & 300 \\
\hline Hungary & 10 & 10 \\
\hline Ireland & - & 80 \\
\hline The Netherlands (multi-year programme 2011-2014) & 500 & 500 \\
\hline Portugal & 30 & 30 \\
\hline Romania & 0 & 40 \\
\hline Spain & - & 30 \\
\hline Sweden & 1900 & 1900 \\
\hline United Kingdom & 750 & 750 \\
\hline TOTAL & 4580 & 4580 \\
\hline
\end{tabular}

Table 6: EU Member States resettlement quota 2012 and 2013; Source: UNHCR (193)

Source: EASO (2013)

\footnotetext{
${ }^{3}$ Percentages are based on data from UNHCR (2013) for the total number of refugees resettled in the world and from EASO (2013) for the total number of asylum applicants granted refugee status in the EU in first instance $(37,335)$ plus final decisions $(13,345): 50,680$.
} 
A lot of attention has been paid to the external borders of the European Union. In addition to direct measures of border control (see below) the EU tries to support Member States that are under particular pressure. For example, the European Asylum Support Office (EASO) started operating in Malta in 2011. Most of the instruments that promote solidarity are in fact means to help guarding Member States at the external border of the European Union, such as Italy or Greece. In 2004, FRONTEX was created as an operational support mechanism for Member States in their management of border controls. FRONTEX has a budget of 90 million Euros. Additionally, the EU Border Surveillance System (EUROSUR) created in 2013 offers a system of organized operational information exchange in order to "reduce the number of migrants entering the EU illegally and to prevent cross border criminality" (Balleix, 2014). Moreover, the Smart Borders Package, which is still under discussion, serves as an additional mean to design border controls in a more efficient manner. Thus, border controls have been at the center of attention over the last decade. Ultimately, those measures may tackle the issues at the external borders of the EU but they do not deal with the question of internal solidarity regarding the allocation of refugees. All those measures may be a first step towards a more solidary union, but they do not suffice to align the needs of all, especially not the preferences of the asylum seekers themselves.

In any event, improving the balance across the EU first requires a proper assessment of the burden carried by each Member State. And indeed, a number of attempts have already been made to assess the current extent of financial burden sharing between EU countries with respect to EU Asylum Policy. Most prominently, Thielemann et al. (2010) estimate the total amount to be distributed in 2008-2013 by the European Refugee Fund to represent only $14 \%$ of the total asylum costs for the EU-27 for the single year 2007. These costs include reception, accommodation, administrative procedures, deportation, integration measures, and so on. They do not however include the opportunity cost of these expensive and inefficient procedures, which would drive up the cost even more, given that it would not be hard to think of more productive uses for these resources. Also, the European Commission (2010) reports that the average cost per relocated refugee can amount to 8,000 Euros, of which selection and travel is just over 1,000 Euros and the rest is accommodation and other support costs. ${ }^{4}$ This is double the actual per refugee budget allowed for relocations under the ERF. Thielemann et al. (2010) even suggest that, under different rules, equal burden

\footnotetext{
${ }^{4}$ This is calculated from a pilot study of transfers between Malta and France.
} 
sharing implies transferring 33 to 40 percent of the asylum seekers currently within the EU to other countries, a large share going to the new Member States. In contrast to the UNHCR "capacity assessment," Thielemann et al. (2010) create a "combined capacity index" that aims to capture whether a country takes in a sufficient amount of asylum seekers according to its potential ability to accommodate them. They show that there is a tremendous discrepancy across EU members with respect to their actual v. "fair share" intake of asylum seekers.

Beyond their quantitative analysis, Thielemann et al. (2010) compare EU countries' Internal Dispersal Systems with those of the United States. The United Kingdom, for example, agrees on the allocation of asylum applicants with local authorities, depending on various parameters, including asylum seekers per person. Conversely, Germany decides upon the dispersal of asylum seekers on the federal level. Regional governments, the Länder, are not involved in the decision making process, which is mainly population-based. In Finland, the main authorities are the municipalities that decide how many asylum seekers they are voluntarily willing to accept. As compensation they receive a small lump-sum that however does not cover the actual costs that are incurred by taking in an additional asylum seeker. Sweden and France take an approach that is more asylum seeker oriented. There, asylum seekers choose freely where to stay. State funds are subsequently transferred to regional governments, according to the total number they host. Compared to the United States, EU Member States base their decision on governmental directives, may they be federal, regional or at the municipal level. In the US however, NGOs (9 agencies plus the State of Iowa) decide how to disperse the resettled refugees across the States.

In general, the policy initiatives of the European Union seem to only alleviate the symptoms of the refugee reception problem, directing their main efforts towards border controls and lump-sum transfers, which do not stand in proportion to the real cost occurring in the host country. Additionally, the burden-sharing assessment has so far only made use of direct costs of refugees, like accommodation or administrative efforts but they do not reveal the true cost (direct costs, indirect costs and opportunity costs) and above all not the underlying benefits, such as the potential economic efficiency gains from receiving immigrants in general or the welfare increase generated by the granting of protection positively valued by public opinion in host countries. These policies thus fail to tackle the problem at the root. In order to adequately assess the cost of refugees and to reveal the preferences of Member States and refugees equally, there is a need for a market-based approach that will efficiently and at a 
low cost lead to the desired social optimum.

\section{Related Literature}

This paper is closely related to two strands of recent literature on the (in)effectiveness of the current EU Asylum Policy, mostly to Hatton (2010, 2011, 2012), for economics, and Thielemann et al. (2010), for political science; and on market-based proposals to address the refugee issue.

Hatton (2012) investigates this question by examining the basis upon which a joint EU policy can be justified and by asking whether a more efficient outcome can be achieved by harmonization alone or a more centralized decision making processes is necessary. He does so by charting the progress of harmonization and burden-sharing in the Common European Asylum System, exploring its costs and benefits, and also analyzes the evolution of public attitudes towards refugees. He also develops a model where asylum is a locally provided public good, thus in its nature underprovided unilaterally. Consequently, this creates the need for a joint policy that ensures an optimal distribution of asylum seekers across Member States. In this case however, a harmonized policy is not sufficient since it does not account for refugees' preferences that may be disproportionately biased towards one destination country. In order to avoid accumulation of refugees in "immigration darlings," there needs to be a joint EU policy that matches supply and demand and prevents oversupply in some and under-provision in other countries. Hatton proposes two different tools to reach (or at least move towards) the social optimum: first, an asymmetric subsidy depending on lack or excess supply of refugees in certain countries, and secondly, an active redistribution of refugees.

As already indicated in section 3.2., Thielemann et al. (2010) calculate fair burden sharing rules according to population size, population density and current stocks of refugees hosted. Any of these suggest a disproportionate distribution of burdens across Member States. In contrast to Hatton (2012), the authors do not suggest a radical shift in the paradigms of asylum policy but, rather, an expansion and enhancement of existing policy tools. Based on surveys asking Member States about their preferences for possible solidarity mechanisms, Thielemann et al. (2010) call for (1) a harmonization of the costs for asylum-seekers, (2) a financial compensation for over-burdened countries, and (3) a voluntary movement of asylum 
seekers from more to less affected states, avoiding costly forced movements. ${ }^{5}$

Overall, the literature has not paid enough attention to market-based solutions. Schuck (1997) and Hathaway and Neve (1997) were first to discuss a system of bilateral negotiations over tradable refugee resettlement quotas. In the words of Schuck (1997, p. 248), "the proposal consists of two main elements. First, a group of states would (...) arrange for an existing or newly-established international agency to assign to each participating state a refugee protection quota. (...) Second, the participating states would then be permitted to trade their quotas by paying others to fulfill their obligations." through bilateral exchange (Schuck, 1997, pp. 283-284). However, Schuck (1997) fell short of proposing a system of tradable quotas as he mostly envisioned the possibility for countries to trade refugees for money on a strictly bilateral basis. Bubb, Kremer, and Levine (2011) supplement this system of bilateral exchange with a screening device to separate refugees from economic migrants. However, the bilateral nature of these proposals limits the scope for trade and, thus, implies an inefficient outcome.

Finally, Fernández-Huertas Moraga and Rapoport (2014) develop a multilateral system of Tradable Immigration Quotas (TIQs) which includes a mechanism to match immigrants to destinations. One of the main applications they envision for their proposed system is the resettlement of long-standing refugees. This would seem a particularly well-suited context for implementing a TIQs system, for a number of reasons. First, refugee protection is a paragon example of international public good, with refugee protection being recognized as a moral and legal obligation by the countries signatories of the 1951 Geneva Convention (and its 1967 extended Protocol) - that is, virtually all the countries of the world. Second, there is also an obvious incentive to free-ride, and not less obvious evidence of ensuing under-provision of refugee resettlement. Third, it is quite common among policymakers to consider refugee protection as a "burden" and there is a general understanding that this burden is not fairly shared at the international level (see, e.g., UNHCR, 2013). And fourth, the institutional framework for international policy coordination is already largely in place, with widely ratified treaties such as the Geneva Convention and existing well-established

\footnotetext{
${ }^{5}$ They emphasize how forced relocations of refugees or asylum seekers are much more expensive than voluntary relocations (ten times more expensive according to a UK report on return that they quote) and this is why they propose that any relocation should be voluntary. From the same report, an example on how to promote voluntary movements is by "better promoting the options available to those due for removal and by establishing better contacts with community groups."
} 
international organizations such as UNHCR.

All these reasons would seem all the more true in the European context, as demonstrated in the previous section. In what follows, therefore, we adapt Fernández-Huertas Moraga and Rapoport (2014) to the context of the EU Asylum Policy by proposing an EU Tradable Refugee-admission Quotas (TRQs) System that takes into account the specifics of the EU context and addresses many of the inefficiencies of the current system. It builds on existing understandings that fair burden sharing rules should be adopted - this is analogous, in our model, to the stage of initial quotas determination - and shows how a TRQs

system can allow for i) truthful revelation of the country-specific costs of accommodating asylum seekers and refugees, ii) exploitation of differences in such costs among EU countries to generate cost-effective outcomes (that is, minimizing total cost for a given number of refugees or maximization the number of refugees for a given budget constraint), and iii) taking refugees' preferences over destinations into account, therefore reducing their incentives to move between countries. Last but not least, the mechanism also allows for taking countries' preferences over refugees' types into account. This can be understood as preferences over refugees' characteristics (such as language, skills, country of origin, etc.) as well as over refugees' legal status (such as asylum seekers in wait for a decision, refugees whose asylum request has been accepted, or internationally resettled refugees), allowing for compensation among countries across refugees' types.

\section{The model}

Our model is a simple extension of the one presented in Fernández-Huertas Moraga and Rapoport (2014) for the case of both asylum seekers and refugees in the context of the European Union.

The model has two building blocks. On the one hand, providing protection to refugees and to asylum seekers with valid claims is considered an international public good. On the other hand, providing protection both to refugees and to asylum seekers, with or without valid claims, is costly so that it can be considered a "burden," which European countries will be sharing through the market.

We proceed in three steps. First, we introduce a basic model for tradable refugee quotas when refugees' and asylum seekers' preferences are not taken into account. Second, we 
add refugees' and asylum seekers' preferences through a matching model. Finally, we also consider receiving countries' preferences over the number the refugees and asylum seekers.

\subsection{Tradable Refugee Quotas without matching}

Suppose each EU country $i$ decides how many refugees and asylum seekers to receive given the net perceived total cost (or benefit) of receiving them: $c_{i}\left(r_{i}, a_{i}\right)$, where $r_{i}$ denotes the number of refugees hosted by country $i$ and $a_{i}$ refers to the number of asylum seekers. We assume that it is convex and differentiable and that it has an interior positive minimum in both arguments.

This cost refers to a set of direct costs, such as:

- Reception and accommodation;

- Administrative procedures;

- Potential removal;

- Potential integration measures, etc.

There are also indirect net costs associated with the admission of refugees and asylum seekers. These include the immigration surplus associated with refugees and asylum seekers (efficiency gains from migration), their net fiscal contribution, their social and political costs, etc.

The international public good aspect is introduced by considering that the inhabitants of the EU receiving countries or at least their governments care about refugees and asylumseekers hosted by other countries through the function $g_{i}\left(R_{-i}, A_{-i}\right)$, with $\frac{\partial g_{i}}{\partial R_{-i}}>0, \frac{\partial g_{i}}{\partial A_{-i}} \geq 0$, $R_{-i}=\sum_{j \neq i} r_{j}$ and $A_{-i}=\sum_{j \neq i} a_{j}$.

Country $i$ would maximize the following welfare function:

$$
\max _{r_{i}, a_{i}} g_{i}\left(R_{-i}, A_{-i}\right)-c_{i}\left(r_{i}, a_{i}\right)
$$

The first order conditions would be:

$$
\frac{\partial c_{i}}{\partial r_{i}}\left(r_{i}^{N C}, a_{i}^{N C}\right)=0=\frac{\partial c_{i}}{\partial a_{i}}\left(r_{i}^{N C}, a_{i}^{N C}\right)
$$


where $N C$ stands for the non-cooperative solution. The number of refugees and asylum seekers hosted by one EU country generates a positive externality for the other EU destination countries. This makes the non-cooperative equilibrium different from the optimal levels of refugees and asylum seekers that should be accepted from the viewpoint of the EU as a whole. We denote these levels as $\left(R^{G O}, A^{G O}\right)$. They are the solution to the problem:

$$
\max _{\left\{r_{i}, a_{i}\right\}_{i=1}^{N}} \sum_{i=1}^{N}\left[g_{i}\left(R_{-i}, A_{-i}\right)-c_{i}\left(r_{i}, a_{i}\right)\right]
$$

Without loss of generality, we can assume that the functions $g_{i}(\cdot)$ are such that $\left(R^{G O}, A^{G O}\right)$ can also be obtained as the solution to the dual problem: ${ }^{6}$

$$
\begin{array}{cc} 
& \min _{\left\{r_{i}, a_{i}\right\}_{i=1}^{N}} \sum_{i=1}^{N} c_{i}\left(r_{i}, a_{i}\right) \\
\text { s.t. } \quad & \sum_{i=1}^{N}\left(r_{i}+a_{i}\right) \geq R^{G O}+A^{G O}
\end{array}
$$

The first order conditions would be:

$$
\frac{\partial c_{i}}{\partial r_{i}}\left(r_{i}^{G O}, a_{i}^{G O}\right)=\lambda=\frac{\partial c_{i}}{\partial a_{i}}\left(r_{i}^{G O}, a_{i}^{G O}\right) \quad \forall i=1 \ldots N
$$

where $\lambda$ is the Lagrange multiplier associated to the constraint. It is easy to see that:

$$
R^{N C}+A^{N C} \equiv \sum_{i=1}^{N}\left(r_{i}^{N C}+a_{i}^{N C}\right)<\sum_{i=1}^{N}\left(r_{i}^{G O}+a_{i}^{G O}\right) \equiv R^{G O}+A^{G O}
$$

If there is no coordination and EU countries act unilaterally, each of them will equalize the marginal cost of accepting one additional refugee or asylum seeker to zero. However, more refugees and asylum seekers would be hosted if countries took into account how other countries care about providing international protection. The optimal solution would be to equalize the marginal net cost of hosting one additional refugee or asylum seeker across countries but not to zero. In a sense, refugees would be hosted where it is "cheapest" to host them from the point of view of cooperative receiving countries. In the presence of

\footnotetext{
${ }^{6}$ See Fernández-Huertas Moraga and Rapoport (2014) for a formulation that solves the maximization problem directly.
} 
cooperation, there would be no need for a "race to the bottom" in terms of each country unilaterally adopting excessively strict policies from the point of view of the EU.

This optimal solution can be replicated by creating a market for tradable refugee quotas. Suppose each country is assigned an initial quota $q_{i 0}$ that can be filled both with refugees and asylum seekers. ${ }^{7}$ These quotas can be traded in a market in which the price received for accepting one additional refugee or asylum seeker into a country is denoted by $p$. The initial distribution of quotas must be agreed upon at the EU level and be such that:

$$
R+A=\sum_{i=1}^{N} q_{i 0}
$$

Three points must be emphasized. First, this would be a non-traditional market in the sense that participation would be restricted, at least initially, to EU governments. Second, the market would not apply to all refugees or asylum seekers at the doors of the EU but only to a predetermined number that Member States would need to agree upon. Third, the system presupposes that the initial distribution of quotas must also be agreed upon at the EU level through some commonly accepted "burden-sharing" rules. This would certainly be a politically sensitive issue and focusing on one particular rule, such as the ones enumerated by Thielemann et al. (2010), is out of the scope of this paper. We only describe briefly below (subsection 5.1.1) some desirable properties for this initial distribution of quotas.

Then, the market would operate in the following fashion:

- Supply of visas (demand for quotas). At a given visa price (higher than their marginal cost), some countries would be willing to get paid to receive refugees in excess of their quota.

- Demand for visas (supply of quotas). At a given visa price (lower than their marginal cost), some countries would be willing to pay to receive less refugees than their quota.

A simple example with two destination countries can illustrate how this market would work. Suppose Australia and New Zealand agree on hosting a given quantity of refugees from Kiribati, denoted by the distance $O_{A}-O_{N Z}$ in Figure 3. They also agree initially that Australia will host $Q$ refugees while New Zealand will take care of the rest. Figure 3 also

\footnotetext{
${ }^{7}$ We can think of alternative formulations in which there would be one quota and one price for each of the categories: refugees and asylum seekers.
} 
depicts the marginal net perceived costs of both countries on the vertical axis, with Australia counting refugees from left to right, so that the net marginal cost increases in the number of received refugees and New Zealand counting them in the opposite direction. If a market for tradable quotas opened between both countries, they would reach an equilibrium quota price at the intersection of both marginal cost curves. At the price marked by this intersection, Australia is willing to get paid to receive more refugees than their allocated quota while New Zealand is willing to pay not to receive them.

\section{Figure 3:}

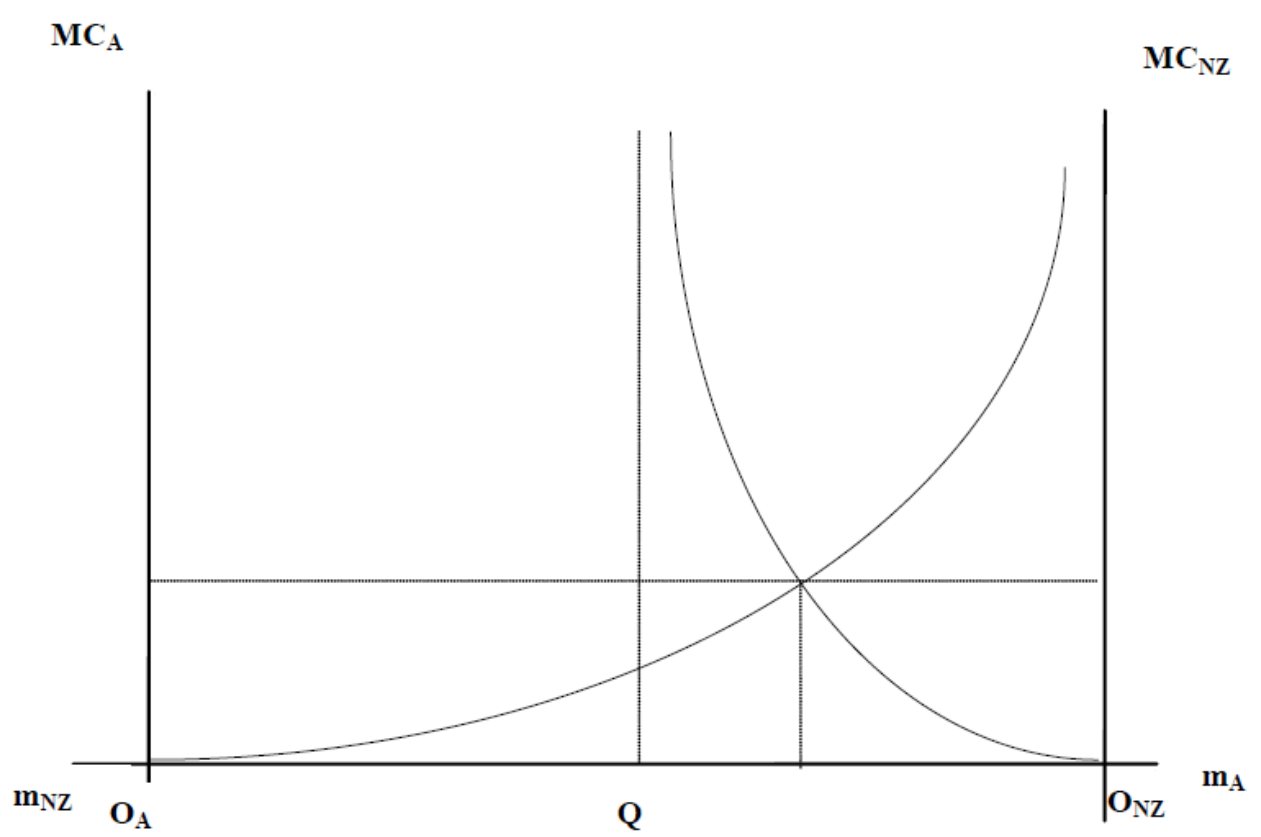

The market will be a Pareto improvement over the non-cooperative solution as long as $R^{N C}+A^{N C}<R+A \leq R^{G O}+A^{G O}$ (Fernández-Huertas Moraga and Rapoport, 2014). It is assumed that the cost functions are expressed in monetary units and that the market is competitive so that all countries behave as price-takers.

Individual countries would then need to solve:

$$
\min _{\left\{r_{i}, a_{i}\right\}} c_{i}\left(r_{i}, a_{i}\right)-p\left(r_{i}+a_{i}-q_{i 0}\right)
$$

The second term means that the cost will be just $c_{i}\left(r_{i}, a_{i}\right)$ as long as the quota is filled: $r_{i}+a_{i}=q_{i 0}$. If country $i$ hosts more refugees and asylum seekers than its quota $\left(r_{i}+a_{i}>q_{i 0}\right)$, 
then its cost will be reduced by this extra amount multiplied by the price $p$. If, on the contrary, it hosts less than its quota $\left(r_{i}+a_{i}<q_{i 0}\right)$, then its cost will be increased by this extra amount multiplied by the price $p$.

If the market is competitive, the first order conditions are:

$$
\frac{\partial c_{i}}{\partial r_{i}}\left(r_{i}^{M}, a_{i}^{M}\right)=p=\frac{\partial c_{i}}{\partial a_{i}}\left(r_{i}^{M}, a_{i}^{M}\right) \quad \forall i=1 \ldots N
$$

The marginal costs of accepting one additional refugee or one additional asylum-seeker are equalized across destinations through the market, which must clear, so that::

$$
R+A=\sum_{i=1}^{N} q_{i 0}=\sum_{i=1}^{N}\left(r_{i}^{M}+a_{i}^{M}\right)
$$

Proposition 1 The market solution to (4) is efficient.

The proof comes from establishing that $p=\lambda$ (Fernández-Huertas Moraga and Rapoport, 2014).

The initial distribution of quotas does not affect the efficiency of the mechanism and it only has redistributive consequences as long as the market is competitive. As discussed in Fernández-Huertas Moraga and Rapoport (2014), this can be achieved through a computerized continuous double auction mechanism, which converges to competitive equilibrium outcomes even when there are very few buyers and sellers thanks to the Bertrand-type competition it promotes (Casella, 1999; Friedman and Ostroy, 1995).

\subsubsection{Taking participation constraints into account}

In addition to its efficiency properties, the market can also be made individually rational for every country through the manipulation of initial quotas. Individual rationality would ensure that every country has an incentive to participate in the market, since it can achieve a better result than by staying out of it.

The general formulation of the problem in which the countries participation constraints are satisfied is:

$$
\max _{\left\{q_{i 0}\right\}_{i=1}^{N}} \sum_{i=1}^{N}\left[g_{i}\left(R_{-i}^{M}, A_{-i}^{M}\right)-c_{i}\left(r_{i}^{M}, a_{i}^{M}\right)\right]
$$




$$
\begin{aligned}
& \text { s.t. } \quad \sum_{i=1}^{N} q_{i 0}=R+A \\
& g_{i}\left(R_{-i}^{M}, A_{-i}^{M}\right)-c_{i}\left(r_{i}^{M}, a_{i}^{M}\right)+ \\
& +p\left(r_{i}^{M}+a_{i}^{M}-q_{i 0}\right) \geq g_{i}\left(R_{-i}^{N C}, A_{-i}^{N C}\right)-c_{i}\left(r_{i}^{N C}, a_{i}^{N C}\right) \quad \forall i=1 \ldots N \\
& \left(r_{i}^{M}, a_{i}^{M}\right)=\arg \min \left\{c_{i}\left(r_{i}, a_{i}\right)-p\left(r_{i}+a_{i}-q_{i 0}\right)\right\} \quad \forall i=1 \ldots N
\end{aligned}
$$

Denoting by $q_{i 0}^{P C}$ the solution to this problem, the first order conditions are:

$$
\begin{aligned}
& \mu-p \pi_{i}=0 \quad \forall i=1 \ldots N \\
& \sum_{i=1}^{N} q_{i 0}^{P C}-R-A=0 \\
& \pi_{i}\left[g_{i}\left(R_{-i}^{M}, A_{-i}^{M}\right)-c_{i}\left(r_{i}^{M}, a_{i}^{M}\right)+p\left(r_{i}^{M}+a_{i}^{M}-q_{i 0}^{P C}\right)-\right. \\
& \left.-g_{i}\left(R_{-i}^{N C}, A_{-i}^{N C}\right)+c_{i}\left(r_{i}^{N C}, a_{i}^{N C}\right)\right]=0 \quad \forall i=1 \ldots N \\
& \pi_{i} \geq 0
\end{aligned}
$$

where $\mu$ is associated to $\sum_{i=1}^{N} q_{i 0}=R+A$ and $\pi_{i}$ is associated to $g_{i}\left(R_{-i}^{M}, A_{-i}^{M}\right)-$ $c_{i}\left(r_{i}^{M}, a_{i}^{M}\right)+p\left(r_{i}^{M}+a_{i}^{M}-q_{i 0}\right) \geq g_{i}\left(R_{-i}^{N C}, A_{-i}^{N C}\right)-c_{i}\left(r_{i}^{N C}, a_{i}^{N C}\right)$. We are using the fact that $\frac{\partial r_{j}^{M}}{\partial q_{i 0}}=\frac{\partial a_{j}^{M}}{\partial q_{i 0}}=0=\frac{\partial p}{\partial q_{i 0}} \forall i, j$ since the solution to the market problem does not depend on the initial allocation of quotas.

From the first set of conditions, we have:

$$
\pi_{i}=\frac{\mu}{p}>0 \quad \forall i=1 \ldots N
$$

This leaves us with a rule to allocate initial quotas satisfying:

$$
\begin{aligned}
& g_{i}\left(R_{-i}^{M}, A_{-i}^{M}\right)-c_{i}\left(r_{i}^{M}, a_{i}^{M}\right)+p\left(r_{i}^{M}+a_{i}^{M}-q_{i 0}^{P C}\right)- \\
& -g_{i}\left(R_{-i}^{N C}, A_{-i}^{N C}\right)+c_{i}\left(r_{i}^{N C}, a_{i}^{N C}\right)=0 \quad \forall i=1 \ldots N
\end{aligned}
$$

which implies: 


$$
\begin{aligned}
q_{i 0}^{P C}=r_{i}^{M}+a_{i}^{M} & +\frac{g_{i}\left(R_{-i}^{M}, A_{-i}^{M}\right)-g_{i}\left(R_{-i}^{N C}, A_{-i}^{N C}\right)}{p}- \\
& -\frac{c_{i}\left(r_{i}^{M}, a_{i}^{M}\right)-c_{i}\left(r_{i}^{N C}, a_{i}^{N C}\right)}{p} \quad \forall i=1 \ldots N
\end{aligned}
$$

The countries benefitting the most from the externality (higher $g_{i}\left(R_{-i}^{M}, A_{-i}^{M}\right)-g_{i}\left(R_{-i}^{N C}, A_{-i}^{N C}\right)$ ) should get higher initial quotas whereas those who deviate most from their individually optimal allocations because of the market (higher $c_{i}\left(r_{i}^{M}, a_{i}^{M}\right)-c_{i}\left(r_{i}^{N C}, a_{i}^{N C}\right)$ ) should get lower initial quotas. Of course, the equality in (14) ensures that the distribution of quotas will obtain the maximum level of total welfare for a given size of the market $(R+A)$. More generally, participation can be obtained with any $q_{i 0} \leq q_{i 0}^{P C}$.

It could be argued that the informational requirements for establishing such a quota are unrealistic so that countries could be unwilling to participate. However, participation constraints are even less clear in the case of signatories of the 1951 Geneva Convention or its 1967 Protocol for the protection of refugees and still 145 countries have signed the former and 146 the latter. They are less clear because they imply countries must host as many individuals as they arrive in their soil as long as they are in danger of persecution in their origin countries. As a result, the potential cost of signing the Convention is not bounded. In our model, the potential cost is bounded by the actual number of refugees and asylum seekers to which the market is applied. Hence, it looks like the externality derived from the provision of this public good is large enough for countries to be willing to enter into this type of multilateral agreements.

\subsection{Taking Refugees' Preferences into Account}

Taking the preferences of refugees and asylum seekers into account is a straightforward task. From a theoretical point of view, the problem is analogous to assigning houses to tenants with existing rights, studied, among others, by Abdulkadiroglu and Sonmez (1999). The existing rights can either refer to the country of first asylum in the EU or to a refugee camp.

Technically, the problem is to assign indivisible items (rights for a refugee or an asylumseeker to enter a given destination country, or "visas") to agents (refugees or asylum-seekers) taking into account their preferences. 
The solution proposed by Abdulkadiroglu and Sonmez (1999) is the use of the top trading cycles mechanism:

1. Each refugee/asylum seeker ranks all potential destination countries, specifying those to which she would not want to go at all.

2. An ordering of refugees and asylum seekers is randomly chosen from a given distribution of orderings. A question remains whether the EU would want to prioritize refugees over asylum seekers.

3. For any given ranking of countries done by the refugees and ordering of refugees, the outcome is obtained using the following algorithm:

(a) Assign the first refugee (from the ordering obtained in step 2) her top choice, the second refugee her top choice among the remaining visas, and so on, until someone requests a visa for which the quota (resulting from the market) is filled. It is as if the first refugee with a visa in that quota is requested to exchange her visa.

(b) If at that point, the refugee whose visa is requested has already chosen before, then go to the second refugee in that quota. If this one has also chosen, go to the third and so on. If the quota is filled with refugees who have already chosen before, then do not disturb the procedure (there is no room for Pareto improvement). Otherwise, modify the remainder of the ordering by inserting the refugee who did not choose yet to the top of the line and go on with the procedure.

(c) Similarly, insert any refugee who is not already served at the top of the line once her visa (to stay in her first asylum country) is requested.

(d) If at any point a loop forms, it is formed exclusively by refugees with a visa each of them requesting the visa of the refugee who is next in the loop (a loop is an ordered list of refugees $\left(j_{1}, j_{2}, \ldots, j_{k}\right)$ where refugee $j_{1}$ requests the visa of refugee $j_{2}$, refugee $j_{2}$ requests the visa of refugee $j_{3} \ldots$, refugee $j_{k}$ requests the visa of refugee $j_{1}$ ). In such cases, remove all refugees in the loop by assigning them the visas they request and continue the procedure.

A key ingredient of this mechanism is that a refugee whose visa is requested is upgraded to the first place at the remaining of the line before her visa is allocated. As a result, 
the top trading cycles mechanism is individually rational, as it assures every refugee a visa that is at least as good as the possibility of staying in her first-asylum country or her refugee camp. It is also incentive compatible (no refugee has an incentive to misrepresent her preferences whatever the strategies others $u^{8} e^{8}$ and Pareto efficient. This is a direct application of Abdulkadiroglu and Sonmez (1999) following directly the exposition in Chen and Sonmez (2002) and substituting word by word house for visa and refugee for tenant. The relevant point for the case of refugees studied here is the possibility that the final allocation determined by the market might not be achieved.

We follow Fernández-Huertas Moraga and Rapoport (2014) to show what the central planner's problem looks like in this case:

$$
\begin{array}{rlr}
\min _{\left\{r_{i}, a_{i}\right\}_{i=1}^{N}} \sum_{i=1}^{N} c_{i}\left(r_{i}^{M M}, a_{i}^{M M}\right) & \\
\text { s.t. } \quad \sum_{i=1}^{N}\left(r_{i}^{M M}+a_{i}^{M M}\right) & \geq R+A & \\
r_{i}^{M M} & =F_{i}\left(r_{1}, r_{2}, \ldots, r_{N} ; a_{1}, a_{2}, \ldots, a_{N}\right) \quad \forall i=1 \ldots N \\
a_{i}^{M M} & =G_{i}\left(r_{1}, r_{2}, \ldots, r_{N} ; a_{1}, a_{2}, \ldots, a_{N}\right) & \forall i=1 \ldots N
\end{array}
$$

The matching mechanism is embedded in the last two lines. The sequence $\left\{F_{i}\right\}_{i=1}^{N}$ of functions $F_{i}:[0, R]^{N} \times[0, A]^{N} \rightarrow[0, R]$ transforms an allocation of visas $\left\{r_{i}, a_{i}\right\}_{i=1}^{N}$ decided by the central planner as if countries were homogenous from the point of view of refugees and asylum seekers into an allocation of visas for refugees $\left\{r_{i}^{M M}\right\}_{i=1}^{N}$ that does take into account refugees' preferences through the matching mechanism (denoted $M M$ ). Similarly, the sequence $\left\{G_{i}\right\}_{i=1}^{N}$ of functions $G_{i}:[0, R]^{N} \times[0, A]^{N} \rightarrow[0, A]$ transforms the allocation of visas $\left\{r_{i}, a_{i}\right\}_{i=1}^{N}$ into an allocation of visas for asylum seekers $\left\{a_{i}^{M M}\right\}_{i=1}^{N}$ that does take into account asylum seekers' preferences through the matching mechanism.

We can approximate both sequences by differentiable functions so that it is simple to write the first order conditions of the problem:

\footnotetext{
${ }^{8}$ This follows directly from individual rationality. Given that an individual whose visa is rejected is upgraded to the first place at the line, there is no incentive to misrepresent preferences since it can only result in a worse outcome for whoever does it.
} 


$$
\begin{array}{ll}
\sum_{j=1}^{N}\left[\frac{\partial F_{j}}{\partial r_{i}}\left(\frac{\partial c_{j}}{\partial r_{j}}\left(r_{j}^{M M}, a_{j}^{M M}\right)-\lambda\right)+\frac{\partial G_{j}}{\partial r_{i}}\left(\frac{\partial c_{j}}{\partial a_{j}}\left(r_{j}^{M M}, a_{j}^{M M}\right)-\lambda\right)\right]=0 & \forall i=1 \ldots N \\
\sum_{j=1}^{N}\left[\frac{\partial F_{j}}{\partial a_{i}}\left(\frac{\partial c_{j}}{\partial r_{j}}\left(r_{j}^{M M}, a_{j}^{M M}\right)-\lambda\right)+\frac{\partial G_{j}}{\partial a_{i}}\left(\frac{\partial c_{j}}{\partial a_{j}}\left(r_{j}^{M M}, a_{j}^{M M}\right)-\lambda\right)\right]=0 & \forall i=1 \ldots N(17)
\end{array}
$$

where $\lambda$ is the multiplier associated with the first constraint.

The equalization of marginal costs across countries is just one possible solution. In particular, it will be the solution whenever the matching mechanism does not distort the planner's allocation.

The TRQ's problem can be formulated as follows:

$$
\begin{array}{r}
\min _{r_{i}, a_{i}} c_{i}\left(r_{i}^{M M}, a_{i}^{M M}\right)-p\left(r_{i}+a_{i}-q_{i 0}\right)+p\left(r_{i}+a_{i}-r_{i}^{M M}-a_{i}^{M M}\right) \\
\text { s.t. } \quad r_{i}^{M M}=F_{i}\left(r_{1}, r_{2}, \ldots, r_{N} ; a_{1}, a_{2}, \ldots, a_{N}\right) \\
a_{i}^{M M}=G_{i}\left(r_{1}, r_{2}, \ldots, r_{N} ; a_{1}, a_{2}, \ldots, a_{N}\right)
\end{array}
$$

The term $p\left(r_{i}+a_{i}-r_{i}^{M M}-a_{i}^{M M}\right)$ is a penalty unattractive countries would have to pay for not being able to attract as many refugees and asylum seekers through the matching mechanism as they would bid for in the market. In equilibrium, the penalty would always be zero but it is needed so that countries do not have incentives to become unattractive from the point of view of refugees and asylum seekers. In practice, the EU could be in charge of collecting this penalty in case of some off-equilibrium behavior.

The objective function can be simplified to $c_{i}\left(r_{i}^{M M}, a_{i}^{M M}\right)-p\left(r_{i}^{M M}+a_{i}^{M M}-q_{i 0}\right)$. It is then easy to write the first order conditions of the problem:

$$
\begin{aligned}
& \frac{\partial F_{i}}{\partial r_{i}}\left(\frac{\partial c_{i}}{\partial r_{i}}\left(r_{i}^{M M}, a_{i}^{M M}\right)-p\right)+\frac{\partial G_{i}}{\partial r_{i}}\left(\frac{\partial c_{i}}{\partial a_{i}}\left(r_{i}^{M M}, a_{i}^{M M}\right)-p\right)=0 \\
& \frac{\partial F_{i}}{\partial a_{i}}\left(\frac{\partial c_{i}}{\partial r_{i}}\left(r_{i}^{M M}, a_{i}^{M M}\right)-p\right)+\frac{\partial G_{i}}{\partial a_{i}}\left(\frac{\partial c_{i}}{\partial a_{i}}\left(r_{i}^{M M}, a_{i}^{M M}\right)-p\right)=0
\end{aligned}
$$

The following proposition holds: 
Proposition 2 Let (18) represent the structure of the problem solved by country $i$ participating in a market for tradable refugee quotas. In particular, the setup of the market is such that country $i$ pays (is compensated) for the actual number of refugees and asylum seekers received $r_{i}^{M M}+a_{i}^{M M}$ rather than by the number bid in the market $r_{i}+a_{i}$, so that $p\left(r_{i}+a_{i}-r_{i}^{M M}-a_{i}^{M M}\right)$ can be considered as a penalty associated to the outcome of the matching mechanism, denoted by $r_{i}^{M M}=F_{i}\left(r_{1}, r_{2}, \ldots, r_{N} ; a_{1}, a_{2}, \ldots, a_{N}\right)$ and $a_{i}^{M M}=$ $G_{i}\left(r_{1}, r_{2}, \ldots, r_{N} ; a_{1}, a_{2}, \ldots, a_{N}\right)$.

Under this definition of a market for tradable refugee quotas, at least one of the market solutions to (15) is efficient, specifically marginal cost equalization across countries.

Again, the proof follows simply from showing $p=\lambda$ (Fernández-Huertas Moraga and Rapoport, 2014).

It turns out that the addition of the matching mechanism to the market for TRQs described in the previous section does not alter its efficiency properties as long as it is properly designed. If participating countries were compensated on the basis of the number of refugees and asylum seekers they bid for in the market, they would have an incentive to bid for a large quota and later on discourage refugees and asylum seekers from going there. This way, they would be compensated by the market in addition to not actually incurring the cost of hosting the refugees and asylum seekers, who would use the matching mechanism not to go to an undesirable destination. In order to prevent this perverse incentive from happening, the solution is to make countries be compensated on the actual numbers of refugees and asylum seekers they host rather than on those they bid for.

This amounts to forcing destination countries to pay the market price for the unfilled part of their quotas. This is a penalty unattractive countries would have to pay for not being able to attract as many refugees and asylum seekers through the matching mechanism as they would bid for in the market. In equilibrium, the penalty would always be zero but it is needed so that countries do not have incentives to become unattractive from the point of view of refugees and asylum seekers. In practice, the EU could be in charge of collecting this penalty in case of some off-equilibrium behavior.

In terms of enforcement, the penalty would generate incentives for countries to abide by their agreements and actually host the number of refugees they accept to host. Of course, collecting the penalty would be an additional enforcement issue but we do not think it different from the enforcement problems associated with the collection of other payments at 
the EU level, whose discussion is out of the scope of this paper.

\subsection{Taking Countries' Preferences into Account}

Not only do refugees and asylum seekers have preferences over the countries to which they can go, but receiving countries also have preferences both between hosting refugees or asylum seekers and possibly about the type (nationality, skill level, etc.) of refugee or asylum seeker they will be hosting as well.

Satisfying these preferences can make hosting refugees and asylum seekers more attractive for host countries. Either the market could be expanded or the same market size could achieve a more cost-effective allocation.

There are at least two ways to introduce countries' preferences into the model. The first and less interesting one would imply creating one market for each type of refugee and asylum seeker there is. For example, if countries only had preferences between refugees and asylum seekers, the EU would just need to create a market for refugee quotas and a market for asylum seekers' quotas.

A second possibility, which we followed in the previous section, is to group refugees and asylum seekers into the same market even if they are heterogeneous. Suppose there are many different types of refugees or asylum seekers over which countries can have preferences in terms of, for example, their nationality or their skill level. We index these different types by $k$ and redefine the total cost function as $c_{i}\left(\boldsymbol{r}_{i}, \boldsymbol{a}_{i}\right)$ where $\boldsymbol{r}_{i}$ and $\boldsymbol{a}_{i}$ are vectors of $K$ elements (types). We assume that the cost function is convex in each of the elements of the vectors and such that the global optimal solution implies higher levels of refugees and asylum seekers than the non-cooperative solution. This way we can use total cost minimization as an alternative to utility maximization. The total minimum cost problem would then be:

$$
\begin{gathered}
\min _{\left\{\left\{r_{i}^{k}, a_{i}^{k}\right\}_{k=1}^{K}\right\}_{i=1}^{N}} \sum_{i=1}^{N} c_{i}\left(\mathbf{r}_{i}^{M M}, \mathbf{a}_{i}^{M M}\right) \\
\text { s.t. } \quad R+A \leq \sum_{i=1}^{N} \sum_{k=1}^{K}\left(r_{i}^{k, M M}+a_{i}^{k, M M}\right) \\
r_{i}^{k, M M}=F_{i}^{k}\left(\mathbf{r}_{1}, \mathbf{r}_{2}, \ldots, \mathbf{r}_{N} ; \mathbf{a}_{1}, \mathbf{a}_{2}, \ldots, \mathbf{a}_{N}\right) \quad \forall i=1 \ldots N ; \forall k=1 \ldots K \\
a_{i}^{k, M M}=G_{i}^{k}\left(\mathbf{r}_{1}, \mathbf{r}_{2}, \ldots, \mathbf{r}_{N} ; \mathbf{a}_{1}, \mathbf{a}_{2}, \ldots, \mathbf{a}_{N}\right) \quad \forall i=1 \ldots N ; \forall k=1 \ldots K
\end{gathered}
$$


For the solution, we would have $N \times K \times 2$ first order conditions:

$$
\begin{aligned}
& \sum_{j=1}^{N} \sum_{l=1}^{K}\left[\frac{\partial F_{j}^{l}}{\partial r_{i}^{k}}\left(\frac{\partial c_{j}}{\partial r_{j}^{l}}-\lambda\right)+\frac{\partial G_{j}^{l}}{\partial r_{i}^{k}}\left(\frac{\partial c_{j}}{\partial a_{j}^{l}}-\lambda\right)\right]=0 \quad \forall i=1 \ldots N ; \forall k=1 \ldots K \\
& \sum_{j=1}^{N} \sum_{l=1}^{K}\left[\frac{\partial F_{j}^{l}}{\partial a_{i}^{k}}\left(\frac{\partial c_{j}}{\partial r_{j}^{l}}-\lambda\right)+\frac{\partial G_{j}^{l}}{\partial a_{i}^{k}}\left(\frac{\partial c_{j}}{\partial a_{j}^{l}}-\lambda\right)\right]=0 \quad \forall i=1 \ldots N ; \forall k=1 \ldots K
\end{aligned}
$$

Still, marginal cost equalization across migrant types and across countries remains a solution to the problem in cases where the matching mechanism does not affect the market outcome.

If the EU sets up a market for tradable refugee quotas in which both countries and refugees and asylum seekers can express their preferences over each other, the formulation of the problem for an individual country would be:

$$
\begin{array}{rll}
\min _{\left\{r_{i}^{k}, a_{i}^{k}\right\}_{k=1}^{K}} c_{i}\left(\mathbf{r}_{i}^{M M}, \mathbf{a}_{i}^{M M}\right)-p \sum_{k=1}^{K}\left(r_{i}^{k}+a_{i}^{k}-q_{i 0}\right)+p \sum_{k=1}^{K}\left(r_{i}^{k}+a_{i}^{k}-r_{i}^{k, M M}-a_{i}^{k, M M}\right) & \\
\text { s.t. } \quad r_{i}^{k, M M}=F_{i}^{k}\left(\mathbf{r}_{1}, \mathbf{r}_{2}, \ldots, \mathbf{r}_{N} ; \mathbf{a}_{1}, \mathbf{a}_{2}, \ldots, \mathbf{a}_{N}\right) & \forall k=1 \ldots K \\
a_{i}^{k, M M} & =G_{i}^{k}\left(\mathbf{r}_{1}, \mathbf{r}_{2}, \ldots, \mathbf{r}_{N} ; \mathbf{a}_{1}, \mathbf{a}_{2}, \ldots, \mathbf{a}_{N}\right) & \forall k=1 \ldots K
\end{array}
$$

The first order conditions associated with this problem are:

$$
\begin{array}{ll}
\sum_{l=1}^{K}\left[\frac{\partial F_{i}^{l}}{\partial r_{i}^{k}}\left(\frac{\partial c_{i}}{\partial r_{i}^{l}}-p\right)+\frac{\partial G_{i}^{l}}{\partial r_{i}^{k}}\left(\frac{\partial c_{i}}{\partial a_{i}^{l}}-p\right)\right]=0 & \forall k=1 \ldots K \\
\sum_{l=1}^{K}\left[\frac{\partial F_{i}^{l}}{\partial a_{i}^{k}}\left(\frac{\partial c_{i}}{\partial r_{i}^{l}}-p\right)+\frac{\partial G_{i}^{l}}{\partial a_{i}^{k}}\left(\frac{\partial c_{i}}{\partial a_{i}^{l}}-p\right)\right]=0 & \forall k=1 \ldots K
\end{array}
$$

The following proposition can be established:

Proposition 3 Let (24) represent the structure of the problem solved by country $i$ participating in a market for tradable refugee quotas. In particular, the setup of the market is such that country $i$ pays (is compensated) for the actual number of refugees and asylum seekers received $\sum_{k=1}^{K}\left(r_{i}^{k, M M}+a_{i}^{k, M M}\right)$ rather than by the number bid in the market $\sum_{k=1}^{K}\left(r_{i}^{k}+a_{i}^{k}\right)$, 
so that $\sum_{k=1}^{K}\left(r_{i}^{k}+a_{i}^{k}-r_{i}^{k, M M}-a_{i}^{k, M M}\right)$ can be considered as a penalty associated to the outcomes of the matching mechanism.

Under this definition of a market for tradable refugee quotas, at least one of the market solutions to (21) is efficient, specifically marginal cost equalization across countries and types.

Once more, the proof follows directly from showing $p=\lambda$ (Fernández-Huertas Moraga and Rapoport, 2014).

Adding a matching mechanism that assigns both destinations to their preferred refugees and refugees to their preferred destinations to the market for TRQs has no effect on the efficiency properties of the market. Marginal cost equalization across migrant types and across countries would still be optimal.

The choice of the appropriate matching mechanism is a different issue. In this case, the preference over one particular mechanism is not that clear. The problem is similar to the allocation of students to colleges (Gale and Shapley, 1962; Roth 1985) although the market and the penalty make it a bit different. Still, Fernández-Huertas Moraga and Rapoport (2014) establish the impossibility of having a stable Pareto-efficient matching mechanism in which countries (colleges) reveal their preferences truthfully over the type of refugees (students) they want, following Roth's (1985) result for the college admissions problem. ${ }^{9}$

Among the many possible matching mechanisms that would be compatible with the market for tradable refugee quotas, we follow Fernández-Huertas Moraga and Rapoport (2014) in arguing for the country-proposing deferred acceptance mechanism, on the basis that it is less manipulable than the refugee-proposing one, as defined by Pathak and Sonmez (2013).

The way the mechanism works is by countries submitting their preferences over refugees and asylum seekers first. Refugees and asylum seekers accept their most preferred visa among the countries willing to accept them and reject the unacceptable ones (countries where they would not want to go). Rejected countries would then offer visas again to their preferred refugees and asylum seekers among those who had not rejected them yet. Refugees and asylum seekers with several visa offers would then hold to their most preferred one and reject their unacceptable ones. The process would repeat until no country would have visas left to offer.

\footnotetext{
${ }^{9}$ Azevedo and Budish (2013) argue that manipulation incentives disappear in deferred acceptance mechanisms as the market grows, though.
} 
Even though this mechanism attains the most preferred stable matching for countries, ${ }^{10}$ taking into account countries preferences could introduce a trade-off. On the one hand, cost-efficiency is increased (Fernández-Huertas Moraga and Rapoport, 2014). On the other hand, the matching mechanism can generate some additional uncertainty over its outcome. However, it must be noted that the first effect can be proved while the second would be an empirical question.

\section{The Malta Example}

This section makes use of a pilot program by the European Union that aimed to implement the principle of solidarity and burden sharing in the context of refugee and asylum policy. Particularly, a European Council Conclusion initiated the EUREMA (European Relocation from Malta) program in 2009 at the initiative of Commissioner Barnier in order to alleviate the disproportionate burden accruing to the Island of Malta. In fact, Malta was under great pressure regarding the large influx of refugees and other asylum seekers in 2009, as well as in 2011 and 2012. The European Asylum Support Office (EASO), whose main objective is to coordinate Member States policies in view of the development of the Common European Asylum System, was inaugurated in Malta in 2011 as a response to these developments and with the objective of evaluating the EUREMA program. EASO (2013) states that:

The Maltese Office of the Refugee Commissioner received a total of 2,114 applications for international protection in 2012 (...). $86.3 \%$ of applications received by the Office of the Refugee Commissioner in 2012, as in previous years, were lodged by third country nationals (TCNs) who entered Malta irregularly by sea. In view of the significant pressures facing Malta, and following an inter-Ministerial pledging conference organised by the European Commission in May 2011, relocation of protected persons from Malta to other Member States took place during 2012 (...). Relocation activities were organised either as part of the EU pilot project on Intra-EU relocation (EUREMA), or through bilateral projects.

EUREMAs success in 2009 led to the extension of the program in 2011 (EUREMA II). EASO divides EUREMA into Phase I, initiated in 2009 and ultimate relocation in 2011, and

\footnotetext{
${ }^{10}$ Azevedo and Leshno (2013) show that it would also be the preferred mechanism for refugees and asylum seekers with a large number of participants.
} 
Phase II, brought to life in 2011 and relocation partly still in process. Tables 2 and 3 show the participating Member States, the pledges, and the final distribution of asylum seekers.

Table 2:

\begin{tabular}{|l|c|c|}
\hline Member State & $\begin{array}{c}\text { Places } \\
\text { pledged }\end{array}$ & $\begin{array}{c}\text { Number } \\
\text { relocated }\end{array}$ \\
\hline France & 90 & 95 \\
\hline Germany & 100 & 102 \\
\hline Hungary & $8-10$ & 0 \\
\hline Luxembourg & 6 & 6 \\
\hline Poland & 6 & 0 \\
\hline Portugal & 6 & 6 \\
\hline Romania & 7 & 0 \\
\hline Slovakia & 10 & 0 \\
\hline Slovenia & 10 & 8 \\
\hline United Kingdom & 10 & 10 \\
\hline Total & $\mathbf{2 5 3 - 5}$ & $\mathbf{2 2 7}$ \\
\hline
\end{tabular}

Source: EASO (2012)

In Phase I, Germany and France relocated most of the immigrants: 197 out of 227, even more than they had pledged initially. In contrast, other countries eventually did not commit to the number of relocations they had pledged at the beginning. In Phase II only 217 out of 306 pledged allocations had effectively taken place by January 2013.

Table 3 shows that participation extended to more countries in this second phase, although this was achieved by allowing some of the new participating countries to sign their own bilateral agreements to relocate refugees and asylum seekers.

The relevance of the EUREMA program for this study is three-fold. First, it sets the context for possible applications of the matching model proposed above. Second, the program applies a simplified matching procedure between Member States and asylum seekers and thus uncovers possible shortcomings and challenges faced by Member States and administrators. 
Table 3:

\begin{tabular}{|l|c|c|l|}
\hline $\begin{array}{c}\text { Member State/Schengen } \\
\text { Associated State }\end{array}$ & $\begin{array}{c}\text { Number of relocation } \\
\text { places pledged } \\
(2011-2012)\end{array}$ & $\begin{array}{c}\text { Number of beneficiaries } \\
\text { relocated } \\
\text { (as at 23 January 2013) }\left({ }^{74}\right)\end{array}$ & \multicolumn{1}{|c|}{$\begin{array}{c}\text { Bilateral/EU funded } \\
\text { project }\end{array}$} \\
\hline Germany & 150 & $63\left({ }^{75}\right)$ & Bilateral \\
\hline Poland & 50 & $20\left({ }^{77}\right)$ & EU-funded Project \\
\hline Spain & 25 & $10\left({ }^{78}\right)$ & Bilateral \\
\hline The Netherlands & 20 & & Bilateral \\
\hline Denmark & 10 & & EU-funderal project \\
\hline Romania & 10 & & EU-funded project \\
\hline Slovakia & 10 & $20\left({ }^{79}\right)$ & EU-funded project \\
\hline Hungary & 5 & $4\left({ }^{80}\right)$ & Bilateral \\
\hline Ireland & 10 & $4\left({ }^{81}\right)$ & EU-funded project \\
\hline Lithuania & 6 & & EU-funded project \\
\hline Portugal & 6 & $\mathbf{2 1 7}$ & EU-funded project \\
\hline Bulgaria & $\mathbf{3 0 6}$ & & \\
\hline Total & & & \\
\hline
\end{tabular}

Table 3: Intra-EU relocation from Malta by EU Member States: number of pledges in 2011-2012 and actual relocations by January 2013

Source: EASO (2013)

Third, it reveals how the proposed matching technique can deal with problems that occur if the relocation is uncoordinated and at which points it is more efficient.

For this purpose, the lessons learned from the EUREMA pilot are of major importance. EASO (2012) analyzes the results in a fact-finding exercise and describes participation, matching procedure, and feedback of the Member States.

Participation in EUREMA was voluntary and, still, 12 EU countries agreed to participate at some point since 2009, when the need of some measure to assist Malta was first brought to the attention of the European Commission. The benefit for participating countries consisted of funding for relocation activities as well as access to the expertise from the designers of the EUREMA framework. This level of participation would be a good sign for a similar pilot experience with a system of tradable refugee quotas like the one presented above.

In addition to the 12 European Member States participating through EUREMA, Phase II also allowed individual countries, both Member States or Associated Countries such as Switzerland, to reach bilateral agreements with Malta for the relocation of refugees or asylum 
seekers. Eight additional countries chose this alternative.

The selection of potential beneficiaries that would be relocated was made in two steps. First, UNHCR counseled potential beneficiaries through a registration exercise that took place in 2009. In a second step, participating countries sent missions to Malta to make the final selection.

The matching part of the market for tradable refugee quotas could follow a similar strategy. During the registration exercise, information could also be gathered about the preferred destinations of all of the potential beneficiaries. Then, countries could express their preferences about types of refugees and asylum seekers and some authority, either UNHCR or EASO, could perform the matching applying the country-proposing deferred acceptance mechanism to both lists of preferences: those of countries and those of potential beneficiaries.

Generally, the fact-finding exercise of EASO reveals that the approach is rather MemberStates oriented. Not only has there been no inquiry about the personal preferences on destinations by refugees and asylum seekers but there is also no or very few information about the satisfaction level of the relocated persons with the EUREMA program. In contrast, there is detailed information about the selection criteria and demands of Member States. Among this detailed information, there is a long list of challenges to be addressed as identified by participating countries. We enumerate a selection of them below, while arguing in which way our market for tradable refugee quotas could have a useful role in addressing them:

- Time constraints relating to identification of candidates, in particular as some required several rounds of counseling before confirming their interest in relocation. The matching mechanism would prevent this type of problem from happening. If we collect the preferences of potential beneficiaries during the registration drive, there would be no need in general to confirm the interest in relocation.

- Limitations and constraints of the participating States' selection criteria, in order to match the profile of beneficiaries of international protection in Malta. Again the matching mechanism, would gather the required information beforehand so that this would no longer be a problem. Participating states could express their limitations and constraints when stating their preferences over types of refugees and asylum seekers.

- Assessing the willingness and suitability of potential beneficiaries to being relocated. This challenge is directly related to the first one and, as in that case, the matching 
mechanism would directly take care of it.

- Target group composition (refugees, subsidiary protection beneficiaries, asylum seekers). In the same way, this challenge is related to the second one so that the part of the matching mechanism that takes care of countries' preferences would address it.

- Setting up clear criteria concerning relatives, especially considering family reunification. This feature is not specifically considered in the current version of the matching mechanism but it can be easily incorporated. For example, Roth (2002) explains how classical matching mechanisms can be modified to take into account the assignment of couples to residency positions in the US.

- Lack of will by some candidates to commit to relocation offers by 'new' EU Member States where there are few migrant communities. Again, this is a matching problem on the side of potential beneficiaries that could be solved by collecting their preferences at the time of registration.

Most of these selected challenges are related to matching issues that can be addressed by the matching mechanism that we incorporate to the market for tradable refugee quotas. This quote from EASO (2012) makes it even clearer (emphasis added):

Some of the selection criteria did not match the characteristics of the beneficiaries of international protection in Malta, making it difficult to carry out the relocation to some of the participating States (...). This sometimes led to a mismatch between the criteria and the pool of candidates (...). Other participating States requested that the beneficiaries be refugees (...).

The last sentence reveals key differences between the admission criteria of several countries. Some preferred already recognized refugees while others were willing to accept asylum seeker waiting for a decision. Figure 4 shows that there was a great deal of heterogeneity in the selection criteria of participating countries.

Out of the ten selection criteria listed, only one of them (language) was mentioned by the ten surveyed countries while two of them (refugee status and not being a threat to public order) were only mentioned by one country (Romania). All in all, this heterogeneity in preferences is good news since it allows exploiting the gains from trade in the market.

We end this section with another quote, this time from EASO (2013): 
Figure 4:

SELECTION CRITERIA

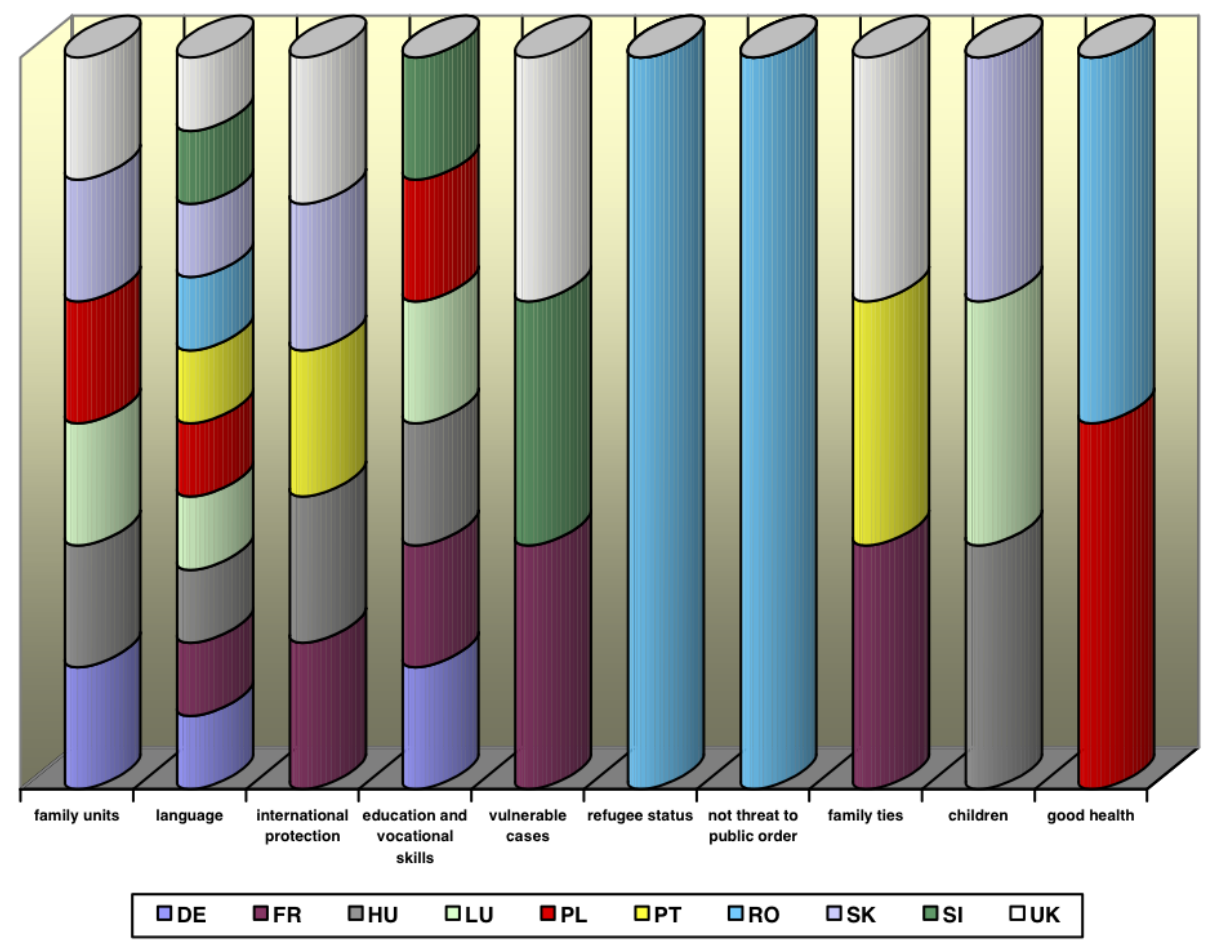

Source: EASO (2012)

... there is room for discussing and developing the instrument of intra-EU relocation in the future, as part of a range of intra-EU solidarity measures. The Commission created the scope for Union co-financing of such activities in the Asylum and Migration Fund proposal, which will facilitate action by Member States willing to engage in voluntary projects, with the EASO taking a coordinating role as established in its founding Regulation.

The main advantage of the proposed matching mechanism is that it deals with the heterogeneity in the preferences of the Member States most efficiently by exploiting the comparative advantage of each participant. Consequently and contrary to conventional EU immigration policies, the matching model embraces heterogeneity rather than trying to find a "one size fits all" solution. As a general conclusion, we argue that, given the Malta example with EUREMA, our proposed market for tradable refugee-admission quotas combined with a matching mechanism would be a perfect instrument for intra-EU relocation of refugees and 
asylum seekers.

\section{References}

[1] Abdulkadiroglu, A. and T. Sonmez (1999): House Allocation with Existing Tenants, Journal of Economic Theory, 88: 233-260

[2] Azevedo, E.M. and E. Budish (2013): Strategy-proofness in the Large, mimeo.

[3] Azevedo, E.M. and J.D. Leshno (2013): A Supply and Demand Framework for TwoSided Matching Markets, mimeo.

[4] Balleix, C. (2014): From Lampedusa to the Post-Stockholm Programme: Diffficult European solidarity in the field of migration. Brussels: Egmont Institute.

[5] Barbou Des Places, S. and B. Deffains (2004): Cooperation in the shadow of regulatory competition: the case of asylum legislation in Europe, International Review of Law and Economics 23: 345-364

[6] Bubb, R., M. Kremer and D. I. Levine (2011): The Economics of International Refugee Law, The Journal of Legal Studies 40 (2): 367-404.

[7] Casella, A. (1999): Tradable Deficit Permits. Efficient Implementation of the Stability Pact, Economic Policy 29: 323-347.

[8] Chen, Y. and T. Sonmez (2002): Improving Efficiency of On-Campus Housing: An Experimental Study, American Economic Review, 92 (5): 1669-1686.

[9] Council (of Ministers) of the European Union (2012), Conclusions on a common framework for genuine and practical solidarity towards member States facing particular pressures on their asylum systems, including through mixed migration flows, 8 March 2012; not published in the Official Journal.

[10] De Bruycker et alia (2010): Setting up a Common European Asylum System: Report on the application of existing instruments and proposal for the new system, Luxembourg: Publications Office of the European Union. 
[11] European Asylum Support Office (2012): EASO fact finding report on intra-EU relocation activities from Malta. Retrieved from http://easo.europa.eu, July 2012.

[12] European Asylum Support Office (2013): Annual Report on the Situation of Asylum in the European Union 2012. Luxembourg: Publications Office of the European Union.

[13] European Commission (2010), Study on the Feasibility of Establishing a Mechanism for the Relocation of Beneficiaries of International Protection, JLX/2009/ERFX/PR/1005, Copenhagen: Directorate General of Home Affairs.

[14] European Commission (2011), Communication on enhanced intra-EU solidarity in the field of asylum: an EU agenda for better responsibility-sharing and more mutual trust $[\operatorname{COM}(2011) 835$ not published in the Official Journal.

[15] European Council (2014): Conclusions concerning the area of Freedom, Security and Justice and some related horizontal issues. 2014/C 240/05.

[16] European Migration Network (2013): Synthesis Report - Intra-EU Mobility of thirdcountry nationals. Brussels: Publications Office of the European Union.

[17] Fernández-Huertas Moraga, J. and H. Rapoport (2014): Tradable Immigration Quotas, Journal of Public Economics 115: 94-108.

[18] Friedman, D. and J. Ostroy (1995): Competitivity in Auction Markets: An Experimental and Theoretical Investigation, The Economic Journal 105 (428): 22-53.

[19] Gale, D. and L. Shapley (1962): College Admissions and the Stability of Marriage, American Mathematical Monthly 69, 9-15.

[20] Hathaway, J. C. and R. A. Neve (1997): Making International Refugee Law Relevant Again: A Proposal for Collectivized and Solution-Oriented Protection, Harvard Human Rights Journal, 10: 115-211.

[21] Hatton, T. J. (2004): Seeking asylum in Europe, Economic Policy, 19 (38): 5-62

[22] Hatton, T. J. (2011): Seeking Asylum. Trends and Policies in the OECD. CEPR. London, UK. 
[23] Hatton, T.J. (2012): Asylum Policy in the EU: the case for deeper integration, Norface Migration Discussion Paper No. 2012-16.

[24] Hatton, T.J. (2013): The Slump and Immigration Policy in Europe, The Australian National University Centre for Economic Policy Research Discussion Paper No. 686.

[25] Neumayer, E. (2004): Asylum Destination Choice: What Makes some European Countries more Attractive than Others?, European Union Politics, 5 (2): 155-180

[26] Pathak, P. and T. Sonmez (2013): School Admissions Reform in Chicago and England: Comparing Mechanisms by Their Vulnerability to Manipulation, American Economic Review 103 (1): 80-106.

[27] Rapoport, H. and J. Fernández-Huertas Moraga (2014): Tradable Refugee-admission Quotas: a Policy Proposal to Reform the EU Asylum Policy, EUI Working Paper RSCAS 2014/101.

[28] Roth, A. E. (1985): The College Admissions Problem is not Equivalent to the Marriage Problem, Journal of Economic Theory 36, 277-288

[29] Roth, A. E. (2002): The Economist as an Engineer: Game Theory, Experimental Economics and Computation as Tools of Design Economics, Econometrica, 70 (4): 13411378.

[30] Schuck, P. H. (1997): Refugee Burden-Sharing: A Modest Proposal, Yale Journal of International Law, 22: 243-297

[31] Thielemann, E.; R. Williams; C. Boswell; and Matrix Insight Ltd. (2010): What system of burden-sharing between Member States for the reception of asylum seekers?. Study. Directorate General for Internal Policies, Policy Department C: Citizens' Rights and Constitutional Affairs, Civil Liberties, Justice and Home Affairs, European Parliament, Brussels.

[32] UNHCR (2013): UNHCR Staistical Yearbook, 12th edition. Geneva: United Nations High Commissioner for Refugees. 